\title{
PROJETO DE SISTEMAS DE DESSALINIZAÇÃO VIA CRISTALIZAÇÃO ASSISTIDA POR DESTILAÇÃO POR MEMBRANAS
}

\author{
C. E. PANTOJA ${ }^{1}$, Y. NARIYOSHI ${ }^{1}$ e M. M. SECKLER ${ }^{1}$ \\ ${ }^{1}$ Universidade de São Paulo, Escola Politécnica, Departamento de Engenharia Química \\ E-mail para contato: cepantoja@usp.br
}

\begin{abstract}
RESUMO - A conjugação da destilação por membranas (MD) com a operação unitária de cristalização dá origem a um processo intensificado denominado Cristalização Assistida por Destilação por Membranas (MDC) que permite recuperar virtualmente toda a água existente em efluentes salinos. Os mecanismos de transporte de calor e massa e aspectos fluidodinâmicos característicos da MD são bem descritos na literatura, porém poucos trabalhos abordam o projeto de sistemas de MDC. Com o auxílio de um modelo matemático rigoroso e de informações heurísticas coletadas da literatura, no presente trabalho foi apresentada uma metodologia para o projeto de sistemas de MDC. Propõe-se um método hierárquico onde as atividades de projeto são divididas em um número limitado de etapas, cada uma delas com escopo bem definido, permitindo a produção de decisões com boa repetibilidade e rastreabilidade em cada nível hierárquico do projeto.
\end{abstract}

\section{INTRODUÇÃO}

O processo de destilação por membranas (MD) tem sido investigado como uma alternativa aos processos evaporativos tradicionais para recuperação da água contida em soluções salinas concentradas (brines), rejeitadas por processos de dessalinização via osmose reversa (OR) e eletrodiálise (ED). A capacidade de produzir fluxos permeados aceitáveis a partir de condições operacionais amenas - temperaturas entre 40 e $80^{\circ} \mathrm{C}$ e pressões próximas à atmosférica - mesmo em sistemas salinos altamente concentrados, motivou a integração da MD com a operação unitária de cristalização em um processo intensificado denominado Cristalização Assistida por Destilação por Membranas (MDC), através do qual é possível separar de forma virtualmente completa a solução salina alimentada em seus constituintes: água pura e cristais de sais (Curcio et al., 2001). No processo de MD, uma membrana hidrofóbica microporosa, normalmente feita de material polimérico, é mantida em contato com uma solução salina aquecida (alimentação, ou retentato) em uma de suas interfaces, sendo a interface oposta mantida em contato com o solvente puro (água) a uma temperatura inferior à da solução salina. $\mathrm{O}$ caráter hidrofóbico da membrana evita que líquido flua de uma interface para outra através dos poros, criando nestes uma interface líquido-vapor em cada lado da membrana. A diferença de temperaturas entre os fluidos em contato com as interfaces da membrana origina um gradiente da pressão de vapor, provocando a evaporação e difusão de moléculas de vapor de água através dos poros cheios de ar. Assim que as moléculas de vapor de água entram em contato com a interface oposta (fria) são imediatamente condensadas e incorporadas ao 


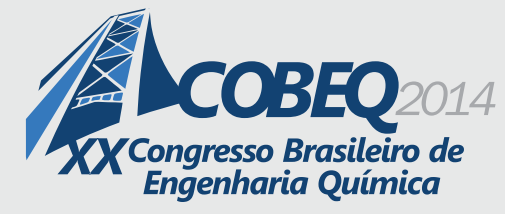

solvente puro, denominado "destilado" ou "permeado" (Curcio e Drioli, 2005). Em MD as membranas são normalmente acondicionadas em módulos tubulares, e seu acoplamento à operação de cristalização pode ser ilustrado pelo fluxograma representado na Figura 1.

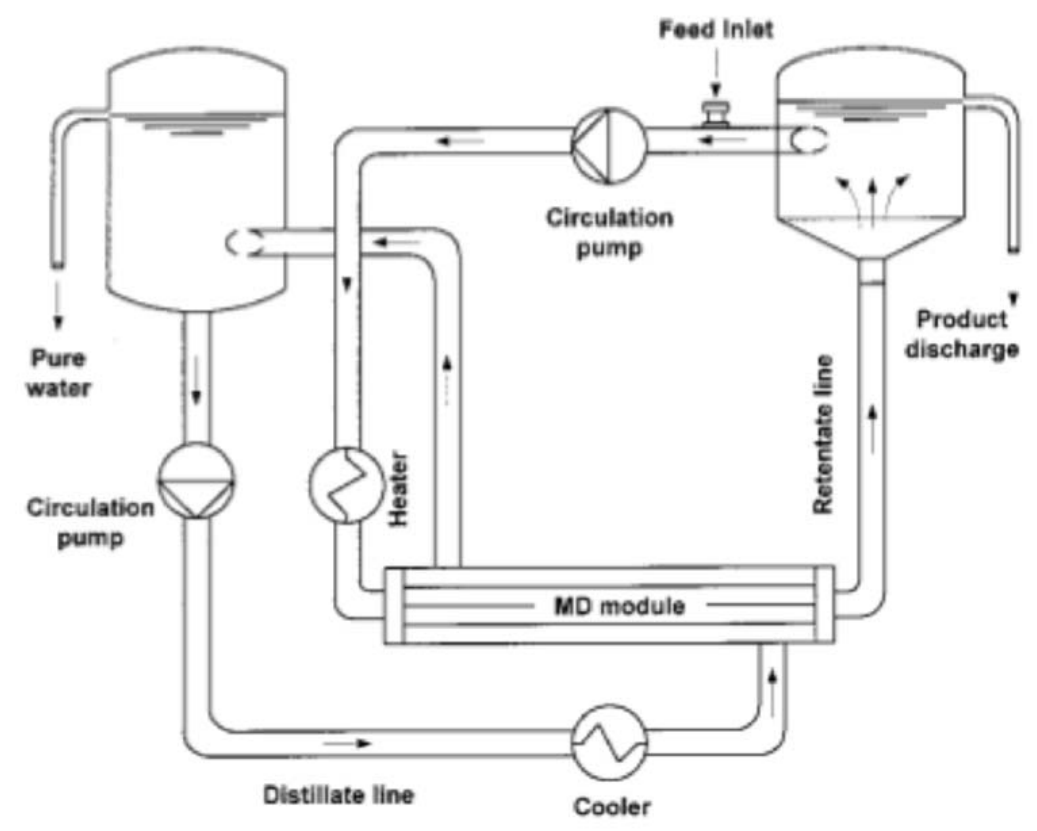

Figura 1 - Fluxograma do processo MDC (Fonte: Curcio et al., 2001).

Os mecanismos de transferência de calor e massa e os aspectos fluidodinâmicos envolvidos na permeação do vapor de água por membranas hidrofóbicas microporosas em MD foram extensivamente investigados nas últimas décadas (Schofield et al., 1987; Lawson e Lloyd, 1996; Curcio et al., 2001; Curcio e Drioli, 2005). Entretanto, apesar de esta tecnologia estar na iminência de ser utilizada comercialmente, não existe praticamente nenhum trabalho dedicado ao projeto de processos de MDC. O presente trabalho tem por objetivo preencher esta lacuna, apresentando uma metodologia consistente e estruturada para abordagem do projeto de um processo de MDC - com o auxílio de um modelo matemático rigoroso criado pelo autor para simulação do módulo tubular de MD acoplado a um cristalizador conforme fluxograma da Figura 1 - e inspirada no método hierárquico de projeto proposto por Douglas (1985) para processos petroquímicos e adaptado por Seckler et al. (2013) para processos de cristalização em solução. Através de tal método, as decisões de projeto são divididas em quatro níveis hierárquicos, onde em cada nível apenas um número limitado de aspectos é considerado, simplificando assim a formulação de hipóteses e respectivas decisões, favorecendo a produção de um projeto com reprodutibilidade, repetibilidade e rastreabilidade.

\section{MÉTODO HIERÁRQUICO: PROJETO DE PROCESSO DE MDC}

Os níveis hierárquicos propostos para o projeto de um processo de MDC são os descritos na Tabela 1 apresentada a seguir: 
Tabela 1 - Níveis hierárquicos no projeto de um processo de MDC

\begin{tabular}{|c|l|}
\hline Nível de Projeto & \multicolumn{1}{|c|}{ Descrição } \\
\hline 0 & Especificações iniciais \\
\hline I & Especificação dos produtos \\
\hline II & Determinação das condições operacionais \\
\hline III & Projeto do módulo de destilação por membranas (MD) \\
\hline IV & Projeto do cristalizador \\
\hline
\end{tabular}

\subsection{Nível 0 - Especificações Iniciais}

Neste nível são especificadas a capacidade nominal da unidade (em termos de vazão de solução salina alimentada), as características da alimentação (composição das espécies iônicas dissolvidas e propriedades físicas) e as utilidades disponíveis no site (fluido de aquecimento para o aquecedor de retentato e fluido de resfriamento para o resfriador de destilado). Por se tratar do rejeito (retentato) de uma unidade de OR ou ED, é esperado que a concentração salina da solução alimentada à unidade de MDC seja superior a $50.000 \mathrm{ppm}$ (em massa), sendo o valor de 70.000 ppm típico para sistemas de dessalinização de água do mar. Quanto à composição, a predominância de íons $\mathrm{Na}^{+} \mathrm{e} \mathrm{Cl}^{-}$é certamente esperada na dessalinização de água do mar, mas também em soluções oriundas de sistemas de tratamento de efluentes aquosos de processos petroquímicos e de refinarias de petróleo, sendo estas últimas de fato o objeto da presente pesquisa, onde o $\mathrm{NaCl}$ representa normalmente mais de $65 \%$ do total de sais dissolvidos (Madwar e Tarazi, 2002). Ainda, supõe-se que contaminantes orgânicos, sólidos em suspensão e sais pouco solúveis já tenham sido removidos nas etapas predecessoras (tratamento primário e secundário, precipitação, $\mathrm{OR}$ e/ou ED). Quanto às utilidades, uma vez que o processo de MDC pode ser conduzido a temperaturas brandas $\left(40-80^{\circ} \mathrm{C}\right)$, sem a necessidade de levar a solução salina à ebulição para remoção do solvente como é o caso de processos evaporativos tradicionais, pode-se utilizar uma fonte de calor de baixa entalpia, como por exemplo uma corrente de reciclo existente no site em questão (que em complexos petroquímicos e refinarias poderá ser facilmente identificada). Fontes alternativas como a energia solar também têm sido utilizadas com sucesso em processos de MD (Charcosset, 2009). Como fonte de resfriamento pode-se utilizar água de torre comum, a temperaturas próximas à ambiente.

\subsection{Nível I - Especificação do Produto}

O processo MDC produz água pura - apenas vapor de água permeia a membrana hidrofóbica microporosa se o processo for conduzido adequadamente - e sais. Em aplicações onde o objetivo principal é a recuperação total da água, caso do objeto do presente trabalho, os sais produzidos são sub-produtos e pouca importância é dada à sua pureza. Entretanto, para que exista boa separação dos cristais da suspensão efluente do cristalizador, o tamanho dos cristais é uma especificação importante. Felizmente, sais muito solúveis como o $\mathrm{NaCl}$ - principal componente do sistema salino em questão conforme destacado no item 2.1 - apresentam taxa de crescimento elevada e formam cristais grandes, da ordem de $10^{-4}$ a $10^{-3} \mathrm{~m}$, caso a supersaturação seja mantida em níveis baixos e o cristalizador seja adequadamente dimensionado. 


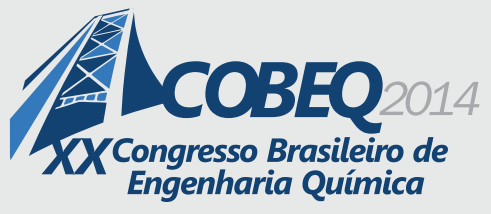

\subsection{Nível II - Determinação das Condições Operacionais}

Temperaturas das correntes: Conforme descrito no item 1, a força motriz do processo de destilação por membranas é, em última análise, a diferença de temperaturas entre a solução salina em contato com um dos lados da membrana (lado quente, retentato) e a água pura em contato com o outro lado (lado frio, destilado). Devido ao comportamento exponencial da pressão de vapor da água com respeito à temperatura do líquido em equilíbrio, quanto maior a temperatura de alimentação do retentato ao módulo de membranas, maior será o fluxo permeado. Da mesma forma, pouca influência no fluxo é observada pela redução da temperatura de alimentação do destilado ao módulo. Os gráficos ilustrados na Figura 2, gerados a partir do modelo rigoroso anteriormente mencionado para um módulo comercial típico, demonstram com clareza esta característica. Assim, quando da seleção das temperaturas das correntes, a maior temperatura possível (dentre as fontes de aquecimento disponíveis no site) deve ser preferida, enquanto que uma fonte de resfriamento com temperatura próxima à ambiente (água de torre de resfriamento, por exemplo) já é suficiente para uma boa condução do processo de MD.

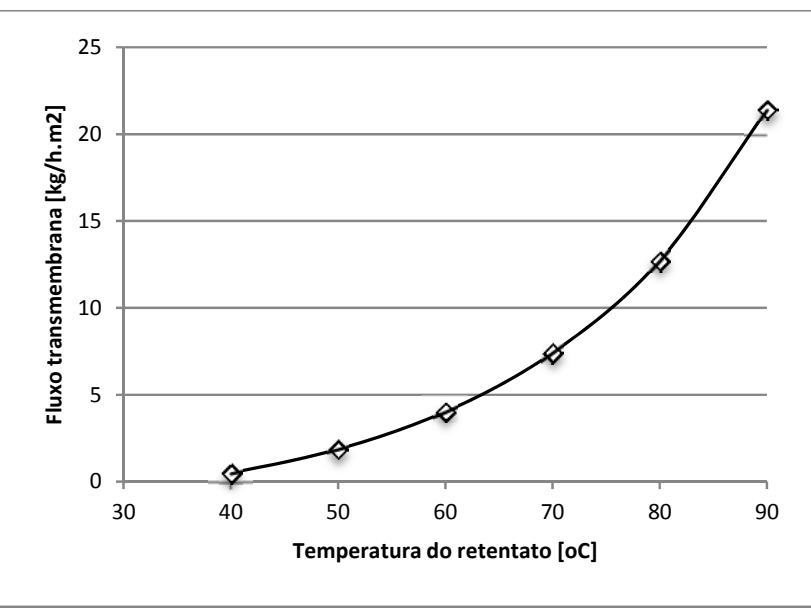

Figura 2a - Fluxo transmembrana em função da temperatura do retentato. Membrana em polipropileno, espessura $450 \mu \mathrm{m}$, poros $0,2 \mu \mathrm{m}$, temperatura de alimentação do destilado $30^{\circ} \mathrm{C}$, regime turbulento (retentato e destilado), solução de $\mathrm{NaCl}$ ligeiramente subsaturada (fração mássica 0,26).

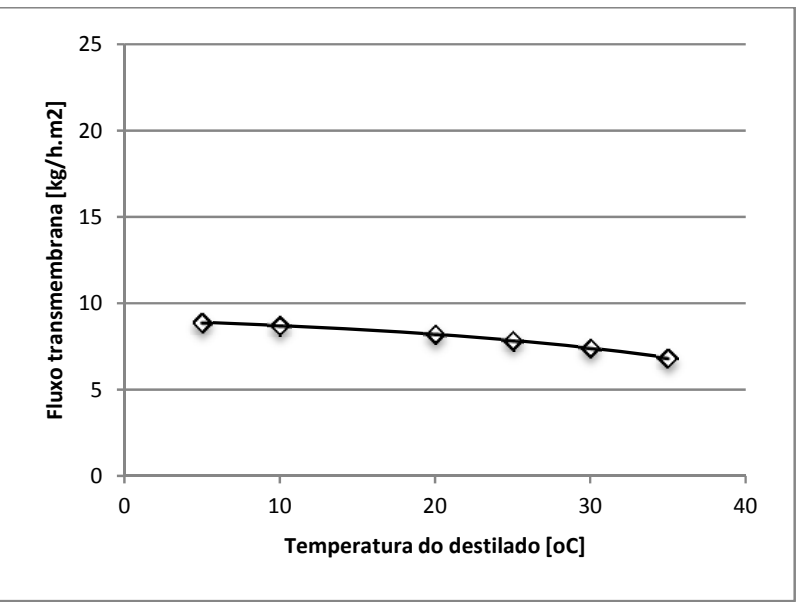

Figura 2b - Fluxo transmembrana em função da temperatura do destilado. Membrana em polipropileno, espessura $450 \mu \mathrm{m}$, poros $0,2 \mu \mathrm{m}$, temperatura de alimentação do retentato $70^{\circ} \mathrm{C}$, regime turbulento (retentato e destilado), solução de $\mathrm{NaCl}$ ligeiramente subsaturada (fração mássica 0,26).

Fluidodinâmica das correntes: O fluxo de vapor através da membrana em um processo de MD é extremamente sensível ao regime de escoamento das correntes (retentato e destilado), principalmente no lado do retentato, devido aos fenômenos de polarização de concentração e polarização de temperatura. Um regime de escoamento turbulento é necessário para minimizar os fenômenos de polarização e consequentemente maximizar o fluxo. Por outro lado, o aumento da turbulência implica em vazões maiores de recirculação das correntes e maior perda de carga através do módulo, o que implica em maior consumo de energia de bombeamento. O gráfico da Figura 3, também gerado a partir do modelo rigoroso, mostra que a partir de determinado valor do número de Reynolds o fluxo tende assintoticamente a um valor máximo, e mostra também que o consumo energético específico 


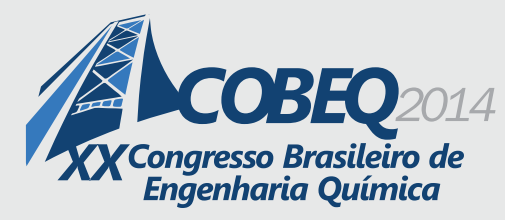

(por massa de destilado produzido) - que compreende o calor fornecido ao aquecedor mais a energia gasta no bombeamento das correntes - diminui com o aumento da turbulência e, a partir de determinado valor do número de Reynolds, tende a aumentar, caracterizando um ponto de energia específica mínima. Em resumo, um número de Reynolds entre 6000 e 8000 no lado do retentato é suficiente para maximizar o fluxo e minimizar o consumo energético do processo. Valores superiores a esta faixa têm pouco impacto no fluxo, apenas aumentando o consumo de energia para bombeamento das correntes.

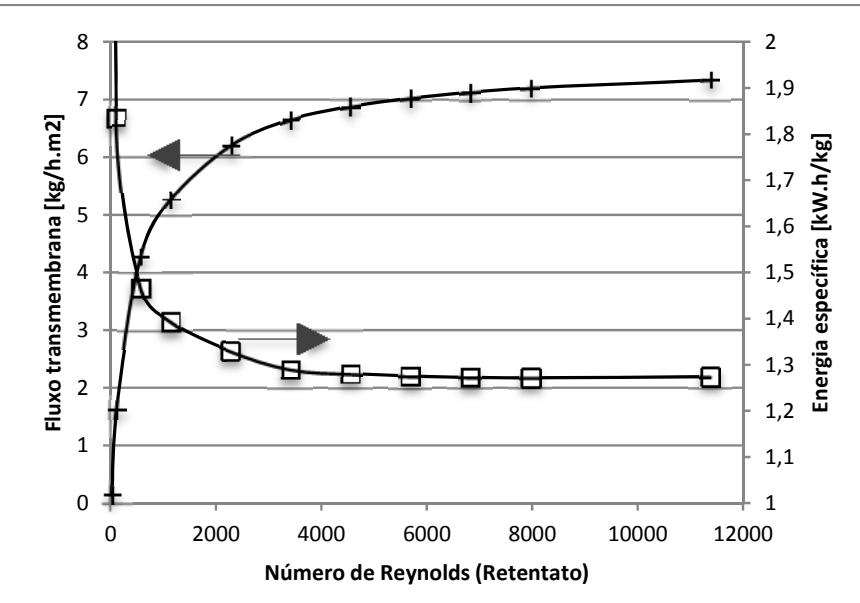

Figura 3 - Fluxo transmembrana e energia consumida em função do número de Reynolds do lado do retentato. Membrana em polipropileno, espessura $450 \mu \mathrm{m}$, poros $0,2 \mu \mathrm{m}$, retentato alimentado a $70^{\circ} \mathrm{C}$ e destilado a $30^{\circ} \mathrm{C}$, solução de $\mathrm{NaCl}$ ligeiramente subsaturada (fração mássica 0,26).

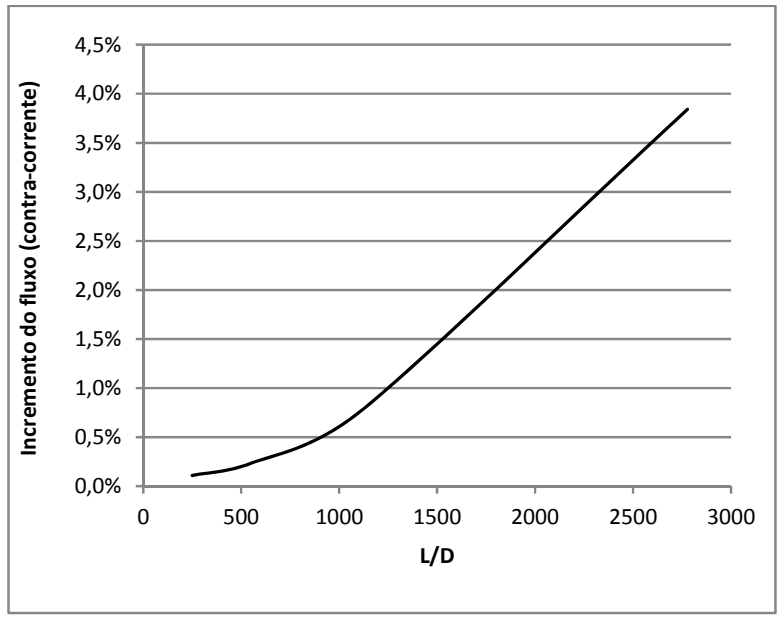

Figura 4 - Incremento do fluxo médio em relação à alocação de correntes em paralelo. Membrana em polipropileno, espessura $450 \mu \mathrm{m}$, poros $0,2 \mu \mathrm{m}$, retentato alimentado a $70^{\circ} \mathrm{C}$ e destilado a $30^{\circ} \mathrm{C}$, solução de $\mathrm{NaCl}$ ligeiramente subsaturada (fração mássica $0,26)$.

Alocação das correntes: Módulos industriais típicos para MD são casco-tubulares, semelhantes a trocadores de calor. As correntes (retentato e destilado) trocam calor ao longo do módulo: seja pela condução de calor pela membrana microporosa, seja pelo calor latente transportado pelo vapor permeado. Assim, existe sempre perda de força-motriz ao longo do módulo, fazendo com que o fluxo seja máximo na extremidade de entrada do retentato e mínimo na extremidade de saída. A exemplo dos trocadores de calor, a alocação das correntes em paralelo ou em contra-corrente tem influência na temperatura terminal das correntes e na quantidade de calor trocada. A teoria de trocadores de calor casco-tubulares demonstra que a troca térmica é maximizada pelo trabalho em contra-corrente, uma vez que a diferença de temperaturas ao longo do trocador é mais ou menos constante, ao contrário da alocação em paralelo, onde a diferença de temperaturas decresce ao longo do trocador, sendo máxima na extremidade de entrada e mínima na extremidade de saída. O fluxo transmembrana em um processo de MD é devido ao transporte simultâneo de calor e massa, e varia exponencialmente com a temperatura do retentato, como já mencionado. Para verificar a melhor configuração de escoamento neste caso, extensivas simulações foram realizadas através do modelo. Foi possível constatar que a configuração em contra-corrente apresenta desempenho ligeiramente superior em MD, sendo tanto melhor quanto maior for a relação L/D do módulo (comprimento em relação ao diâmetro dos tubos). 


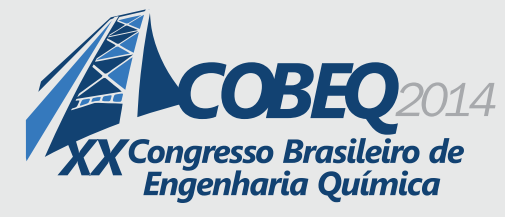

Assim, para módulos com L/D reduzido, menor que 1000, a alocação das correntes praticamente não tem interferência no fluxo, conforme ilustra a Figura 4.

\subsection{Nível III - Projeto do Módulo de Destilação por Membranas}

Espessura da membrana: Quanto mais espessa a membrana, maior sua resistência à transferência de massa. Por outro lado, membranas mais espessas diminuem a transferência de calor por condução (efeito potencializado pela presença de ar nos poros), diminuindo assim a perda de força-motriz e a eficiência térmica do processo. Com o auxílio do modelo matemático foram efetuadas simulações para várias espessuras de membrana, sendo os resultados para o fluxo e o consumo energético ilustrados na Figura 5. Verifica-se que a partir de uma certa espessura, o consumo energético do processo MD estabiliza-se, indicando que a perda de calor por condução foi minimizada, sendo a transferência de calor entre as correntes devida quase que exclusivamente ao calor latente transportado pelo vapor. O fluxo, entretanto, continua decrescendo, embora não de forma linear, à medida em que a espessura aumenta. É possível dizer, portanto, com alguma segurança, que a espessura ótima encontra-se entre 30 e $80 \mu \mathrm{m}$. Valores inferiores a $30 \mu \mathrm{m}$ correspondem a fluxos elevados, porém a um alto custo energético, enquanto que valores superiores a $80 \mu \mathrm{m}$ produzem fluxos menores sem entretanto qualquer redução no consumo de energia do processo.

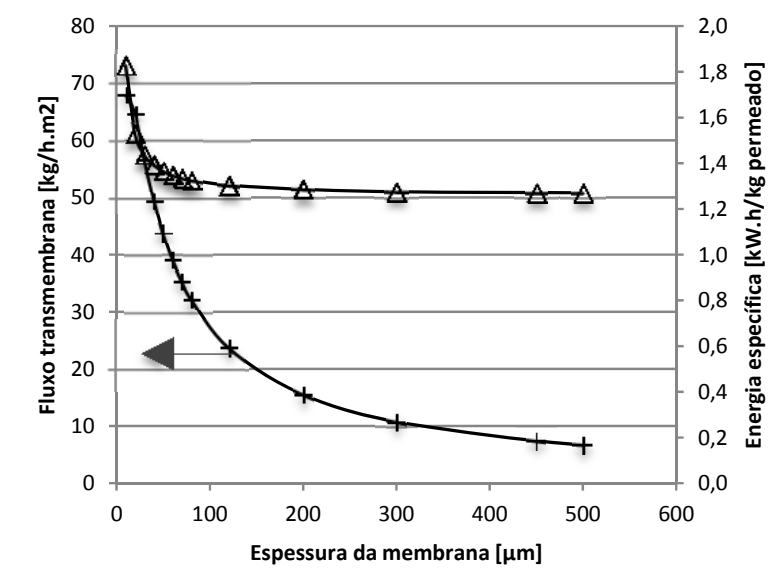

Figura 5 - Fluxo transmembrana em função da espessura da membrana. Membrana em polipropileno, poros $0,2 \mu \mathrm{m}$, alimentação de retentato a $70^{\circ} \mathrm{C}$ e destilado a $30^{\circ} \mathrm{C}$, regime turbulento.

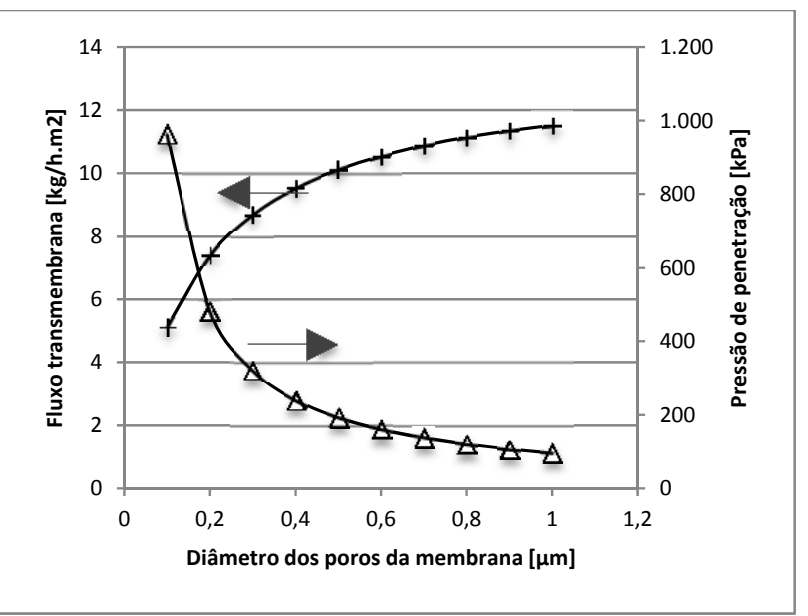

Figura 6 - Fluxo transmembrana em função do tamanho dos poros. Membrana em polipropileno, espessura $450 \mu \mathrm{m}$, alimentação de retentato a $70^{\circ} \mathrm{C}$ e destilado a $30^{\circ} \mathrm{C}$, regime turbulento.

Diâmetro dos poros: Membranas utilizadas em MD apresentam poros com diâmetros que variam entre $0,1 \mu \mathrm{m}$ e $1,0 \mu \mathrm{m}$. Poros pequenos apresentam maior resistência à transferência de massa, devido à maior influência da difusão de Knudsen (choques das moléculas de vapor com as paredes dos poros). Por outro lado, fluxos mais elevados ocorrem em poros maiores, porém com maior possibilidade de "molhamento" da membrana, ou seja, passagem de líquido através da mesma. Existe assim um compromisso entre a maximização do fluxo e a minimização da possibilidade de molhamento, a qual é controlada pela pressão de penetração, ou LEP. Como as pressões ao longo do 


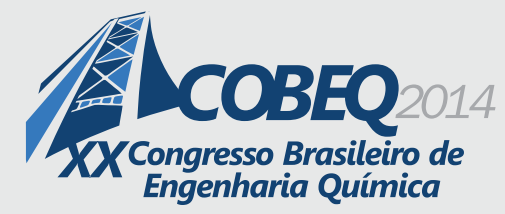

19 a 22 de outubro de 2014

Florianópolis/SC

sistema estão sob controle do projetista (o modelo matemático em questão prevê, por exemplo, a perda de carga no lado dos tubos e no lado do casco do módulo), é possível a seleção do maior diâmetro de poro que não provoque molhamento. O gráfico da Figura 6 mostra a variação de ambas as grandezas - fluxo e LEP - em função do diâmetro dos poros, para uma membrana típica de MD em condições de processo também típicas.

L/D ótimo: Conforme anteriormente descrito, o fluxo varia ao longo do módulo tubular, devido à queda de temperatura do retentato. Quanto mais longo o módulo, menor a temperatura de saída do retentato e menor, portanto, o fluxo médio resultante. Da mesma forma, maior será a temperatura de saída do destilado quanto maior o comprimento do módulo. A Figura 7 ilustra com simulações o fluxo máximo, mínimo e médio para módulos de membranas tubulares com diversos comprimentos, mas com número e diâmetro de tubos fixos, a partir de condições operacionais fixas (vazão e temperatura de entrada das correntes). A partir de um L/D maior do que 5000 (onde L é o comprimento dos tubos e D o diâmetro interno dos tubos), o fluxo mínimo, ou seja, o fluxo na extremidade de saída do retentato, tende a zero. Simulações adicionais foram realizadas para outras temperaturas de alimentação de retentato, e também a partir de L/D $>5000$ o fluxo tendeu a zero na extremidade de saída do mesmo. Pode-se, portanto, estabelecer um $\mathrm{L} / \mathrm{D}=5000$ como o máximo efetivo para um módulo de MD em processos de MDC. Qual seria, entretanto, o L/D ótimo? Para responder a esta questão foram estimados o custo de investimento (módulo de membranas, trocadores de calor e bombas de circulação) e o custo operacional (energia elétrica para as bombas, água de resfriamento e depreciação). Não foi considerado o custo de aquecimento, partindo-se do pressuposto que uma fonte de calor de baixa entalpia estaria a priori disponível no site, sendo sua energia descartada caso não fosse utilizada no processo de MDC. Os resultados são ilustrados pela Figura 8, podendo ser simplificadamente explicados da seguinte forma: para um dado $\mathrm{L} / \mathrm{D}$, existe um fluxo médio correspondente, que por sua vez determinará a área total de membrana requerida para o processo. A fluidodinâmica ótima para o retentato, determinada no Nível II, aliada a uma velocidade econômica de escoamento para os tubos previamente definida pelo projetista (no caso, da ordem de 1,5 m/s), determina simultaneamente o diâmetro e o número de tubos, bem como a vazão por tubo e, consequentemente, a vazão total de circulação de retentato pelo módulo. Os resultados obtidos pelo modelo demonstraram que valores de $\mathrm{L} / \mathrm{D}$ menores estão associados a áreas de membrana menores e vazões de circulação maiores (módulos mais curtos, mas com maior número de tubos), com variações menores nas temperaturas de entrada e saída dos fluidos recirculados pelo módulo (retentato e destilado). Finalmente, a análise econômica dos resultados das simulações apontou para um L/D ótimo, que minimiza os custos totais (custo de investimento mais custo operacional), da ordem de 2000-2500.

\section{CONCLUSÕES}

Foi proposto um método hierárquico de projeto para sistemas de MDC. Com o auxílio de um modelo matemático rigoroso para o módulo de MD acoplado a um cristalizador, foi possível estabelecer níveis de decisão de projeto bem definidos: no Nível 0 as especificações inicias do processo são especificadas; no Nível I as especificações dos produtos são determinadas; no Nível II (condições operacionais), concluiu-se que temperaturas maiores para o retentato são indicadas, com Reynolds ideal entre 6000 e 8000 e alocação de correntes em contra-corrente para L/D>1000; no 


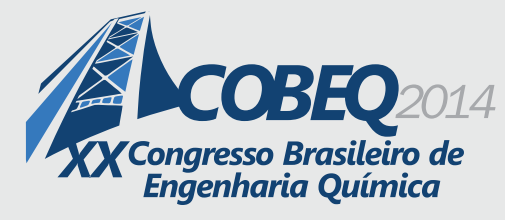

Nível III especificações ótimas para o módulo MD foram determinadas, como espessura da membrana entre $30 \mu \mathrm{m}$ e $80 \mu \mathrm{m}$, diâmetro de poros entre $0,1 \mu \mathrm{m}$ e $1,0 \mu \mathrm{m}$, maximizados de acordo com a LEP admissível, e L/D entre 2000 e 2500. O Nível IV (projeto do cristalizador) não foi abordado no presente trabalho e será discutido futuramente.

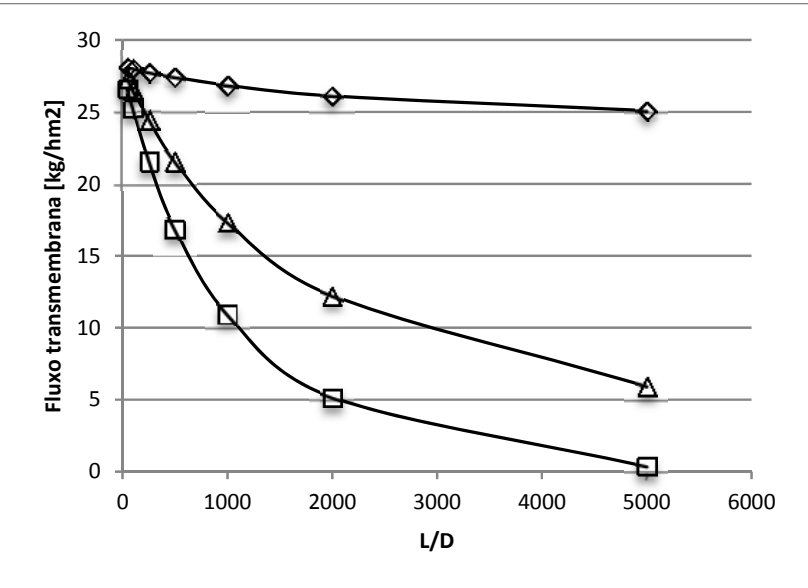

Figura 7 - Fluxo máximo, mínimo e médio em função do $\mathrm{L} / \mathrm{D}$ do módulo. Alimentação de retentato a $70^{\circ} \mathrm{C}$ e destilado a $30^{\circ} \mathrm{C}$, regime turbulento.

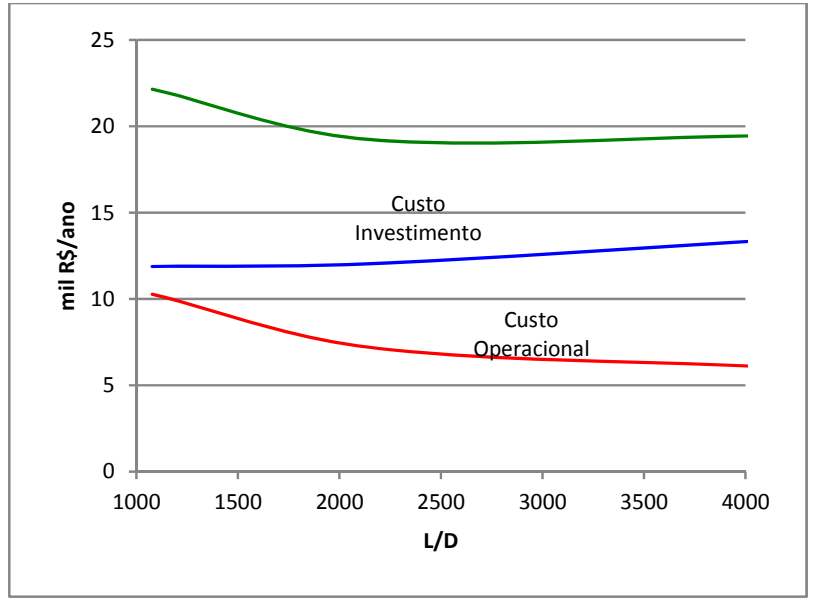

Figura 8 - L/D ótimo para módulo de MD em processo de MDC. Alimentação de retentato a $70^{\circ} \mathrm{C}$ e destilado a $30^{\circ} \mathrm{C}$, regime turbulento.

\section{REFERÊNCIAS}

CHARCOSSET, C. A review of membrane processes and renewable energies for desalination. Desalination, v. 245, p. 214-231, 2009.

CURCIO, E.; CRISCUOLI, A.; DRIOLI, E. Membrane crystallizers. Ind. Eng. Chem. Res., v. 40, p. 2679-2684, 2001.

CURCIO, E.; DRIOLI, E. Membrane distillation and related operations - A review. Sep. \& Purif. Review, v. 34, p. 35-86, 2005.

DOUGLAS, J.M. A hierarchical decision procedure for process synthesis. AIChE Journal, v. 31, p. 353-362, 1985.

LAWSON, K.W.; LLOYD, D.R. Membrane distillation. I. Module design and performance evaluation using vacum membrane distillation. J. Membrane. Sci., v. 120, p. 111-121, 1996.

MADWAR, K.; TARAZI, H. Desalination techniques for industrial wastewater reuse. Desalination, v. 152, p. 325-332, 2002.

SCHOFIELD, R.W.; FANE, A.G.; FELL, C.J.D. Heat and mass transfer in membrane distillation. J. Membrane. Sci., v. 33, p. 299-313, 1987.

SECKLER, M.M.; GIULIETTI, M.; BERNARDO, A.; DERENZO, S.; CEKINSKI, E.; SILVA, A.N.; KRAMER, H.J.M.; BOSCH, M. Salt crystallization on a $1 \mathrm{~m}^{3}$ scale: From hierarchical design to pilot plant operation. I\&EC Research, 2013. 